\title{
Antioxidant responses and lipid peroxidation in Mozambique tilapia (Oreochromis mossambicus) exposed to phenol and m-cresol
}

\author{
REMYA VARADARAJAN AND BABU PHILIP \\ Department of Marine Biology, Microbiology and Biochemistry, Cochin University of Science and Technology \\ Fine Arts Avenue, Kochi - 682 016, Kerala, India \\ e-mail:drbabuphilip@gmail.com
}

\begin{abstract}
The present study evaluated phenol and m-cresol induced oxidative stress responses in the teleost fish Oreochromis mossambicus in a semi-static test system in which water was renewed every $24 \mathrm{~h}$. Fishes were exposed to sublethal $\left(1 / 10\right.$ of $\left.\mathrm{LC}_{50} / 96 \mathrm{~h}\right)$ concentration of phenol $\left(3.12 \mathrm{mg} \mathrm{l}^{-1}\right)$ and m-cresol $\left(2.2 \mathrm{mg} \mathrm{l}^{-1}\right)$ for a period of 21 days. Significant increases in catalase (CAT) and superoxide dismutase (SOD) activities in gills, liver and kidney of treated groups represent an adaptive response to free radical toxicity. Reduction in enzyme activity shows that all reactive oxygen species (ROS) are not being quenched. Glutathione-S-transferase (GST) activity was found to be highly elevated in liver which may be due to its important role in the detoxification of xenobiotics. Total reduced glutathione glutathiore peroxidase (GSH) level was found to be highest in liver which may be an adaptive mechanism to oxidative stress. An increased hydroperoxide (HP) level was observed in liver, kidney and muscle of both the treated groups which may be attributed to the decreased glutathione peroxidase (GPx) activity observed. Increased malondialdehyde (MDA) levels in gills and liver indicates that elevated antioxidant enzyme activities were not efficient enough to prevent lipid peroxidation in these tissues. Taken as a whole, the present results seem to implicate that phenolic compounds are potent mediators of free radical generation in fish.
\end{abstract}

Keywords: Lipid peroxidation, Oreochromis mossambicus, Oxidative stress, Phenolic compounds, Reactive oxygen species, Tilapia

\section{Introduction}

Sewage and industrial waste influx into natural water bodies result in the introduction of several phenolic compounds from industrial sources such as wood processing plants, petroleum refineries, coal producers and other chemical plants. Aquatic biota uptake these pollutants directly from water, sediments, suspended and particulate matter. Among the different phenolic compounds, phenols and cresols are widely used as organic solvents. These compounds have also been identified in water soluble fractions of crude oil since they are potential degradation products of aromatic hydrocarbon metabolism (Saeed and Al-Mutairi, 1999). Phenol is a toxic metabolite of benzene, an ubiquitous industrial and environmental pollutant (Michele, 1994). Because of its antiseptic properties, phenol finds use in hospitals as common disinfectant and in throat lozenges and mouthwashes. Phenol is described as ecotoxic by the Environmental Protection Agency of the United States (USEPA) and is maintained in the priority list. Cresols (monomethyl derivatives of phenol) (commercial grade) contains approximately 20\% o-cresol, 40\% m-cresol, and 30\% p-cresol. m-cresol is used to produce certain herbicides, as a precursor to the pyrethroid insecticides, to produce antioxidants, and to manufacture the explosive, 2, 4, 6-trinitro-m-cresol. Creosote is a combination of natural phenols, primarily guaiacol and creosol and is classified as a hazardous substance for occupational exposure (Deichmann and Keplinger, 1981).

The imbalance between the generation and the neutralisation of reactive oxygen species (ROS) by antioxidant mechanisms within an organism is called oxidative stress (Davies, 1995). The presence of phenolic compounds in aquatic environments is undesirable because they perturb free radical processes and are highly toxic to aquatic organisms. Therefore biomarkers of oxidative stress in the gills, liver, kidney and muscle of Oreochromis mossambicus exposed to different phenolic compounds were investigated. Oxidative stress was evaluated by measuring indicators of the integrity of the antioxidant defense system such as the non-enzymatic antioxidant glutathione (GSH) and antioxidant enzymes such as catalase (CAT), superoxide dismutase (SOD), glutathione peroxidase (GPx) and glutathione-S-transferase (GST). Analysis of the extent of lipid peroxidation is also crucial since ROS can attack and oxidize the fatty acid side chains of phospholipids. Hence indicators of lipid peroxidation such as malondialdehyde (MDA), hydroperoxide (HP) and conjugated dienes (CD) were also estimated. 


\section{Materials and methods}

\section{Test compounds and chemicals}

Analar monohydric phenol $\left(\mathrm{C}_{6} \mathrm{H}_{5} \mathrm{OH}\right)$ and m-cresol $\left(\mathrm{C}_{7} \mathrm{H}_{8} \mathrm{O}\right)$ (SRL, India) were used. For all the experiments, desired concentrations of phenolic compounds were prepared from fresh stock solutions. All other chemicals used for biochemical investigations were of analytical grade and the biochemicals and reagents were purchased from Merck and Himedia.

\section{Experimental animals and maintenance}

Freshwater fish $O$. mossambicus commonly known as tilapia was selected as the experimental animal since it satisfies almost all the conditions for the choice of a standard fish in toxicological studies (Adelman and Smith, 1976). Tilapia of size $15 \pm 3 \mathrm{~g}$ were collected from the culture ponds of Kerala Agricultural University, Puduvypu, Kochi, India and brought to the laboratory in tanks equipped with filters and oxygenation systems. The fishes were kept in aquaria for a 30 days acclimatisation period and were maintained in freshwater with dissolved oxygen content of $7.8 \mathrm{ppm}$, hardness below detectable amounts, $\mathrm{pH} 7.0 \pm 0.37$ and temperature $26 \pm 3^{\circ} \mathrm{C}$. The animals were fed on commercial dry feed pellets (Higashu) ad libitum.

\section{Lethal toxicity studies}

Acclimatised fish were sorted into batches of eight each and kept in 1801 polypropylene tanks containing dechlorinated tap water to maintain biomass theory $\left(\operatorname{lg~} 1^{-1}\right)$. To avoid variations in concentrations of phenolic compounds, solutions were renewed every $24 \mathrm{~h}$ (EPA, 2002). The fish were randomly distributed in different concentrations of phenol and m-cresol. For the acute bioassay tests, 8 fishes per tank, in three replicates were used for each treatment dose and for the control group. The number of dead fishes were counted every $24 \mathrm{~h}$ during the $96 \mathrm{~h}$ assay period and were removed immediately from the aquaria. Control groups were subjected to the same protocol, but without phenolic compounds. Water in the control as well as treatment tanks as well as the desired concentration of phenolic compounds in the experimental tanks were renewed every $24 \mathrm{~h}$ (semi-static assay system). The $\mathrm{LC}_{50}$ levels and 95\% confidence limits were calculated by probit analysis (Finney, 1971) using SPSS 13.0 package.

\section{Sublethal toxicity studies}

Acclimated fishes $(15 \pm 3 \mathrm{~g})$ were divided into three groups, (in triplicates of 6 fishes per tank) for control and sublethal concentrations of phenol and m-cresol. Sublethal concentrations of phenol and $\mathrm{m}$-cresol, corresponding to $10 \%$ of the $96 \mathrm{~h} \mathrm{LC}_{50}$ of the respective compounds were used. The system water was renewed every $24 \mathrm{~h}$ (semi-static) with the same concentrations of phenolic compounds so as to maintain the concentration. The exposure period was for 21 days (OECD, 2000).

\section{Tissue samples}

On termination of the 21 days experiment, fishes were killed by pithing, liver, gills, kidney and muscle tissues were dissected out and then blood and other body fluids were removed using blotting paper. The tissues were washed in ice cold $0.33 \mathrm{M}$ sucrose (isotonic for fish), blotted dry and the desired amounts of tissues were weighed and used for analyses.

\section{Parameters investigated}

SOD activity was assayed using the method of Kakkar et al. (1984). Specific activity was expressed as units mg protein ${ }^{-1}$. CAT activity was assayed according to the method of Maehly and Chance (1955). The estimation was done spectrophotometrically following the decrease in absorbance at $230 \mathrm{~nm}$ (One IU = Change in absorbance at $230 \mathrm{~nm} \mathrm{~min}{ }^{-1}$ Extinction coefficient $\left.=0.021\right)$. GPx activity was estimated by the method of Rotruck et al. (1973). Values are expressed as $\mu \mathrm{g}$ of GSH $\mathrm{min}^{-1} \mathrm{mg}$ protein $^{-1}$.

GST activity was determined using the method of Beutler (1986). The extinction coefficient of CDNB-GSH conjugate is $9.6 \mathrm{mM}^{-1} \mathrm{~cm}^{-1}$. Values are expressed in $\mu$ moles of CDNB (1-chloro-2, 4-dinitrobenzene) complexed $\mathrm{min}^{-1}$ $\mathrm{mg}$ protein ${ }^{-1}$. Total reduced glutathione was estimated by the method of Ellman (1959). Values were expressed as nanomoles per $100 \mathrm{~g}$ wet tissue. Hydroperoxide was estimated by method of Mair and Hall (1971). Molar extinction coefficient of hydroperoxide is $1.73 \times 10^{4} \mathrm{M}^{-1} \mathrm{~cm}^{-1}$. The level of conjugated diene was estimated according to the method of Retnagol and Ghoshal (1966). Molar extinction coefficient of conjugated dienes is $2.52 \times 10^{4} \mathrm{M}^{-1} \mathrm{~cm}^{-1}$. Malondialdehyde was estimated by the method of Niehaus and Samuelson (1968). The extinction coefficient for malondialdehyde is $1.56 \times 10^{5} \mathrm{M}^{-1} \mathrm{~cm}^{1}$. The values of $\mathrm{CD}$, HP and MDA are expressed as millimoles per $100 \mathrm{~g}$ wet tissue. Protein was estimated by the method of Lowry et al. (1951) using bovine serum albumin as standard.

Effects of sublethal concentrations of phenol and $\mathrm{m}$-cresol for 21 days on biomarkers of oxidative stress in gills, liver, kidney and muscle tissues of O. mossambicus were statistically analysed by one-way ANOVA followed by Tukey's test. Significance level (p value) was set at 0.05 in all tests. 


\section{Results and discussion}

$\mathrm{LC}_{50}$ values and confidence limits estimated by Finney's probit analysis (EPA, 2002) in semi-static tests for $96 \mathrm{~h}$, for phenol and m-cresol are presented in Table 1 and 2 respectively. The $96 \mathrm{~h} \mathrm{LC}_{50}$ values of $O$. mossambicus estimated for phenol and m-cresol were 31.25 and 22.2 $\mathrm{mg} \mathrm{l}^{-1}$ respectively.

Table 1. Estimated lethal concentration values and confidence limits for phenol

\begin{tabular}{llcc}
\hline Point & $\begin{array}{l}\text { Concentration } \\
\left(\mathrm{mg} \mathrm{l}^{-1}\right)\end{array}$ & \multicolumn{2}{c}{$95 \%$ confidence limits } \\
\cline { 3 - 4 } & & Upper & Lower \\
\hline LC 1.00 & 20.87 & 18.23752 & 20.54003 \\
LC 5.00 & 23.39 & 22.02694 & 23.70293 \\
LC 10.00 & 26.01 & 24.03901 & 25.39712 \\
LC 25.00 & 27.84 & 27.36783 & 28.26129 \\
LC 50.00 & 31.25 & 30.91383 & 31.59615 \\
LC 75.00 & 34.65 & 34.19388 & 35.19696 \\
LC 90.00 & 37.72 & 37.04368 & 38.54016 \\
LC 95.00 & 39.56 & 38.73456 & 40.55553 \\
LC 99.00 & 43.00 & 41.89457 & 44.34785 \\
\hline
\end{tabular}

Table 2. Estimated lethal concentration values and confidence limits for m-cresol

\begin{tabular}{llcc}
\hline Point & $\begin{array}{l}\text { Concentration } \\
\left(\mathrm{mg} \mathrm{l}^{-1}\right)\end{array}$ & \multicolumn{2}{c}{$95 \%$ confidence limits } \\
\cline { 3 - 4 } & 17.90399 & 16.87248 & Upper \\
\hline LC 1.00 & 19.16376 & 18.44528 & 19.69338 \\
LC 5.00 & 19.83534 & 19.27902 & 20.21762 \\
LC 10.00 & 20.95752 & 20.64800 & 21.19066 \\
LC 25.00 & 22.20434 & 22.00865 & 22.43217 \\
LC 50.00 & 23.45116 & 23.12495 & 23.91803 \\
LC 75.00 & 24.57334 & 24.07677 & 25.30823 \\
LC 90.00 & 25.24492 & 24.64056 & 26.14604 \\
LC 95.00 & 26.50469 & 25.69360 & 27.70000 \\
\hline LC 99.00 & 2.59 & & \\
\hline
\end{tabular}

The antioxidant defense mechanism of O. mossambicus was found to be responsive to the exposure of different phenolics during the present study. Xenobiotics such as phenol are metabolised by the multi-enzymatic system cytochrome P450 (CYP) (Andersson and Forlin, 1992) to products such as hydroquinones, catechols and benzoquinones. SOD activity (Fig. 1a) was found to be significantly $(\mathrm{p}<0.05)$ elevated in gills, liver and kidney of $O$. mossambicus treated with phenol compared to control and among these tissues, liver showed the maximum activity. Fishes treated with m-cresol showed significantly $(p<0.05)$ elevated activity in liver, kidney and muscle compared to control group. The tissue specific SOD activity showed significant $(\mathrm{p}<0.05)$ increase in fishes treated with phenol in the order, kidney $>$ gills $>$ liver whereas the muscle showed significantly low SOD activity compared to control. Toxic stress can alter the activity of SOD in the vital tissues of fish (Sreejai and Jaya, 2010). Kappus and Sies (1981) reported that the superoxide radical by itself or after its transformation to $\mathrm{H}_{2} \mathrm{O}_{2}$ caused a strong oxidation of the cysteine in the enzyme and decrease in the SOD activity. On treatment with $\mathrm{m}$-cresol, tissues such as liver, kidney and muscle showed a significantly $(p<0.05)$ elevated activity whereas gills showed significantly decreased activity compared to control. Changes in the levels of SOD have been detected in fishes exposed to various degrees of oxygen tension (Lushchak et al., 2001) and environmental perturbations (Achuba, 2002). Catechol, one of the biotransformation products of phenolics increases the reduction of $\mathrm{O}_{2}$ and this may have resulted in an increased SOD activity. Also catechol reduces the dismutation of $\mathrm{O}_{2}$ and thus leads to the production of larger amounts of $\mathrm{H}_{2} \mathrm{O}_{2}$.

For the detoxification of increased $\mathrm{H}_{2} \mathrm{O}_{2}$ generated, a significantly $(\mathrm{p}<0.05)$ elevated CAT activity was observed in gills, liver and kidney of fishes treated with both the phenolics (Fig. 1b) compared to control group. Highest CAT activity was found in the liver of fishes treated with m-cresol. An increased generation of $\mathrm{H}_{2} \mathrm{O}_{2}$ may have occurred due to several reasons such as oxygen depletion (Penning et al., 1996) and dismutation reaction of $\mathrm{O}_{2}$ catalysed by increased SOD activity.The SODCAT system provides the first defense against oxygen toxicity. Perhaps a peroxisomal proliferation may have also occurred (Mannaerts and Van Veldhoven, 1993) and the proliferation may have resulted in elevated CAT activity and presumably prevents accumulation of this toxic compound. Considering the results for each tissue in both treated groups, it was found that liver showed the highest SOD and CAT antioxidant activity, both enzymes appearing to have an important role in combating the sequential generation of superoxide radical $\left(\mathrm{O}_{2}^{-}\right)$and hydrogen peroxide $\mathrm{H}_{2} \mathrm{O}_{2}$ from the intense metabolic activity characteristic of this tissue. Increase of SOD and CAT in liver is reported in some fish species under oxidative stress (Bainy et al., 1996; Sayeed et al., 2003; Gull et al., 2004; Zhang et al., 2004; Nam et al., 2005; Wilhelm-Filho et al., 2005). The significant increase in CAT and SOD activities observed in gills, liver and kidney may represent an adaptive response to protect the fish from free radical toxicity induced by phenolic compounds.

GPx activity (Fig. 1c) significantly $(\mathrm{p}<0.05)$ decreased in gills, liver and kidney of the treated groups compared to control group. Whereas muscle in both treated groups showed significantly $(\mathrm{p}<0.05)$ enhanced GPx activity compared to control. The key enzymes involved in the removal of $\mathrm{H}_{2} \mathrm{O}_{2}$ in cytoplasm are CAT and GPx, but only the GPx activity was decreased in O. mossambicus exposed 


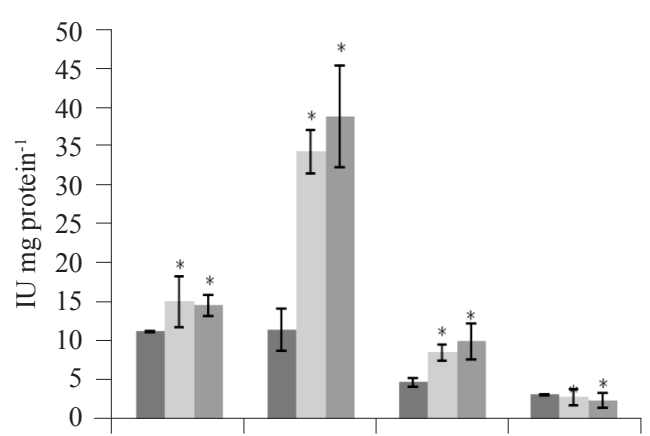

(a)

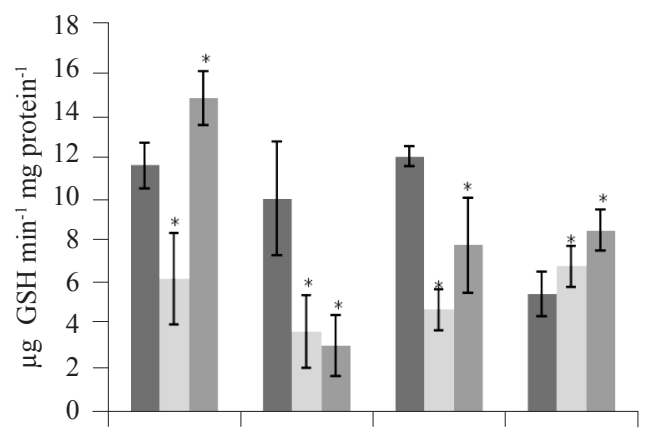

(c)

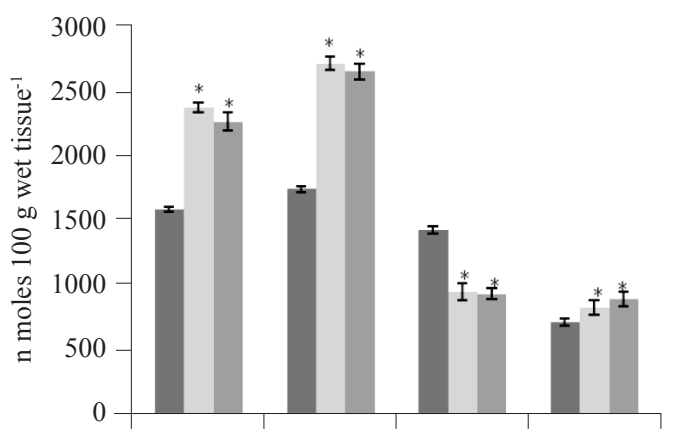

(e)

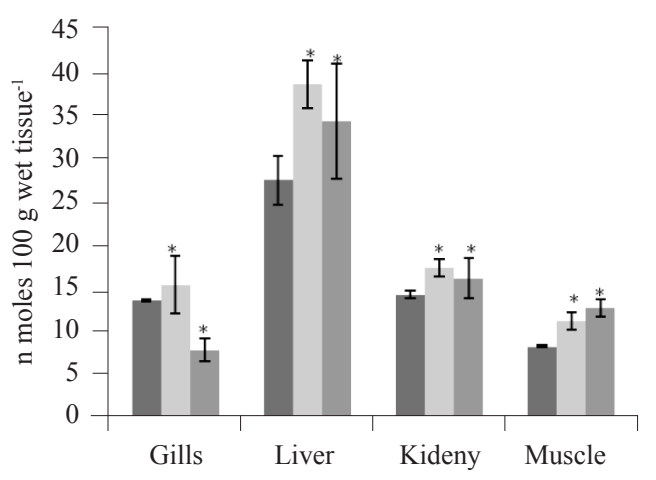

(g)

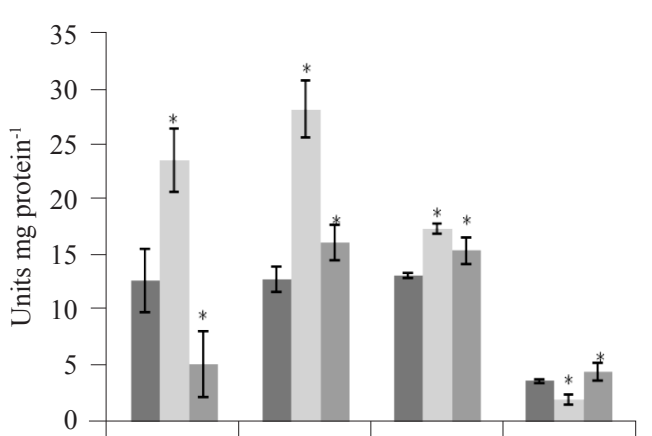

(b)

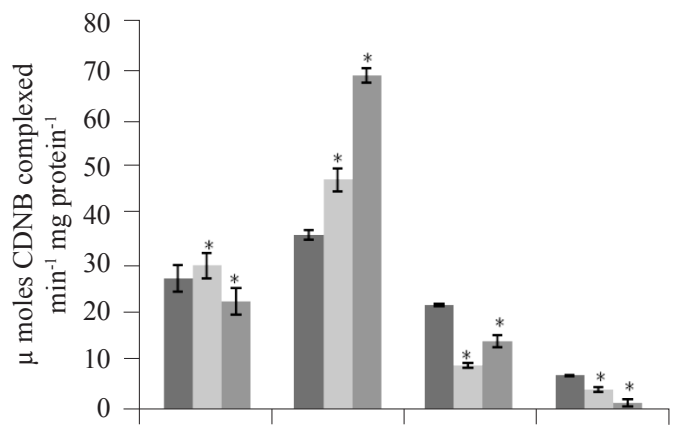

(d)

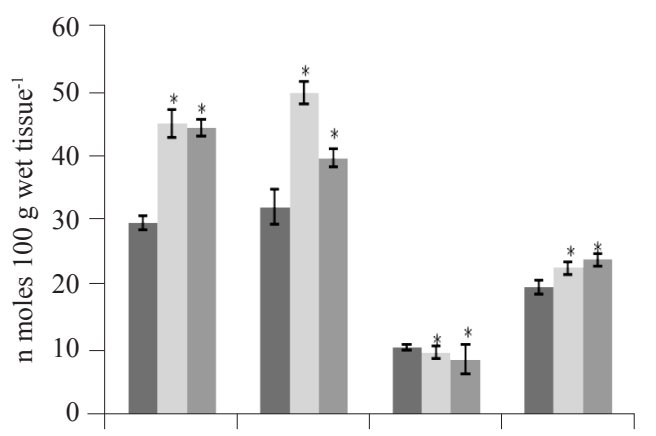

(f)

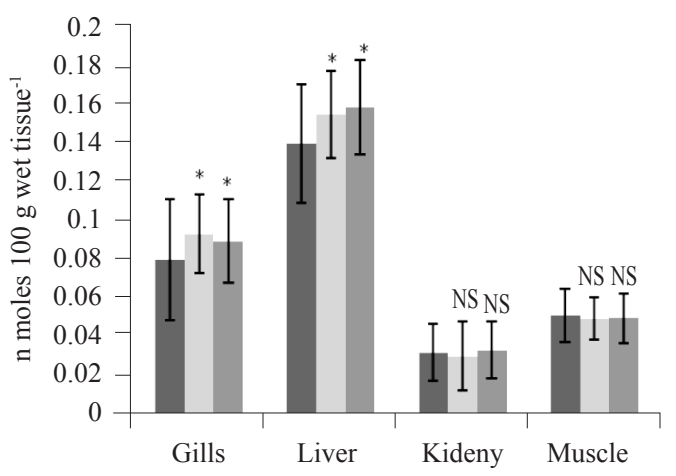

(h)

$\square$ Control, $\square$ Phenol, $\square$ M-cresol

Fig.1. Effect of phenolic compounds on indicators of oxidative stress in $O$. mossambicus. Each bar represents mean \pm S.D for $\mathrm{n}=6$. On each set of bars, significant difference are marked by $(*)$ for $p<0.05$ compared to the respective control (One-way ANOVA) (a) SOD activity, (b) CAT activity, (c) GP x activity, (d) GST activity, (e) GSH level, (f) HP level, (h) CD level 
to both the phenolics. A reduction in enzyme activity shows that all ROS are not being quenched, thus subjecting the cells to oxidative stress. The low GPx activity might be due to a direct phenol inhibition of enzyme synthesis or due to increased generation of $\mathrm{H}_{2} \mathrm{O}_{2}$ which may have inhibited the enzyme activity. Also catechol toxicity is mainly associated with damage to the protein and generation of $\mathrm{H}_{2} \mathrm{O}_{2}$, which is capable of causing further damage (Barreto et al., 2009). Significantly elevated GPx activity in muscle probably indicate an induction in GPx activity in this tissue.

Among the tissue samples collected from fishes treated with different phenolic compounds, liver showed significantly $(\mathrm{p}<0.05)$ highest GST activity (Fig. 1d). This may be because liver plays an important role in the detoxification of xenobiotics and in their elimination by conjugating them with glutathione. There are reports indicating the role of induced GST activity in protection against the toxicity of xenobiotic-induced lipid peroxidation (Leaver and George, 1998). Many studies analysing GST activity in liver of fish exposed to different insecticides showed an enzymatic induction (Andersson et al., 1985; Rodriguez-Ariza et al., 1991; Leaver et al., 1992; Scott et al., 1992). Metabolites formed from detoxification of foreign compounds act as substrates for GST and modify the microsomal glutathione transferase covalently. This results in increasing the enzyme activity by which these reactive metabolites are eliminated through conjugation. This would allow the cells to adjust rapidly to exposure of reactive compounds. The microsomal metabolism of phenol to species which will bind to proteins is most likely catalysed by $\mathrm{P} 450$ monooxygenases (Sawahata and Neal, 1983; Wallin et al., 1985). These enzymes are probably the major targets for the covalent binding of phenol. It is likely that the electrophilic metabolites, benzoquinone and 2-hydroxybenzoquinone conjugate with the sulphydryl group of the enzyme, thereby activating the enzyme (Irons, 1981).

GST activity was found to be significantly $(p<0.05)$ inhibited in kidney and muscle on exposure to different phenolic compounds. Also, an inhibition of GST activity has been reported in gills of mosquito fish exposed to carbofuran (Rondon et al., 2005).

Tissues such as gills, liver and muscle showed significantly $(p<0.05)$ elevated GSH levels (Fig. 1e) compared to those samples from control on exposure to both the phenolics. Among the tissues, GSH levels was found to be highest in liver compared to other tissues which may be due to an adaptive mechanism to slight oxidative stress through an increase in its synthesis. Kidney in both the treated groups showed significantly $(\mathrm{p}<0.05)$ reduced GSH levels compared to control group. However, a depletion of GSH observed in kidney suggests that severe oxidative stress may suppress GSH levels due to loss of adaptive mechanisms and the oxidation of GSH to glutathione disulfide (GSSG). During scavenging the ROS, GSH gets oxidised and forms glutathione-protein mixed disulphides. The efficiency of cell to manage the oxidative stress is dependent on the cell's ability to reduce or synthesise GSH. It has been reported that total glutathione will be a prospective biological index to indicate exposure to contaminants (Stein et al., 1992).

Significantly $(p<0.05)$ elevated CD level (Fig. 1f) was observed in both the treated groups in tissues such as gills, liver and muscle whereas the kidney in both the treated groups showed a significantly $(p<0.05)$ reduced level compared to control. CD is the initial peroxidative product and is an accurate indicator of lipid peroxidation and its elevated level indicated that lipid peroxidation has been initiated.

Gills, liver, kidney and muscle from the treated fishes showed significantly $(\mathrm{p}<0.05)$ elevated HP levels (Fig. 1g) compared to control. Among the tissues, the highest level of HP was seen in liver. This may be because of the decreased GPx activity observed in these tissues as this enzyme catalyses the reduction of peroxides formed from oxidation of lipids. GPx prevents lipid peroxidation (Winston and Di Giulio, 1991), which may have resulted in an elevated HP level. Being more polar than parent lipids, hydroperoxides perturb membrane structure/ function and can be deleterious to cells (Girotti, 1998). MDA level (Fig. 1h) showed significantly $(\mathrm{p}<0.05)$ elevated levels in gills and liver compared to control indicating that elevated antioxidant enzyme activities were not efficient enough to prevent lipid peroxidation in these tissues. MDA is an important product formed due to peroxidation of polyunsaturated fatty acids. No significant variation in MDA level was found in gills, kidney and muscle of both the treated groups compared to control. An overall indication of oxidative stress in target organs was observed and hence it can be concluded that phenolic compounds are a potent mediator of free radical generation in fish.

\section{Acknowledgements}

Authors wish to thank Cochin University of Science and Technology and University Grants Commission (UGC-RFSMS), New Delhi for the financial support.

\section{References}

Achuba, F. I. 2002. Superoxide dismutase and lipid peroxidation levels in fish from the Ethiope River in southern Nigeria. Bull. Environ. Contam. Toxicol., 69: 892-899. 
Adelman, I. R., Smith, L. L. Jr., and Siesennop, G. D. 1976. Acute toxicity of sodium chloride, pentachlorophenol, glutathione and hexavalent chromium to fathead minnow (Pimephales promelas) and goldfish (Carassius auratus). J. Fish. Res. Board Canada, 33: 203-208.

Andersson, T. and Forlin, L. 1992. Regulation of the cytochrome P450 enzyme system in fish. Aquat. Toxicol., 24: 1-20.

Andersson, T., Pesonen, M. and Johansson, C. 1985. Differential induction of cytochrome P-450 dependent monooxygenase, epoxide hydrolase, glutathione transferase and UDP-glucuronosyl transferase activities in the liver of the rainbow trout by $\beta$-naphthoflavone or Clophen A50. Biochem. Pharmacol., 34(18): 3309-3314.

Bainy, A. C. D., Saito, E., Carvalho, P. S. M. and Junqueira, V. B. C. 1996. Oxidative stress in gill, erythrocytes, liver and kidney of Nile tilapia (Oreochromis niloticus) from a polluted site. Aquat. Toxicol., 34: 151-162.

Barreto, G., Madureira, D., Capani, F., Aon-Bertolino, L., Saraceno, E. and Alvarez-Giraldez, L. D. 2009. The role of catechols and free radicals in benzene toxicity: An oxidative DNA damage pathway. Environ. Mol. Mutagen., 50: 771-780.

Beutler, E., 1986. Red cell metabolism. Churchill Livingstone Publishing, New York, 70 pp.

Davies, K. J. A. 1995. Oxidative stress: the paradox of aerobic life. Biochem. Soc. Symp., 61: 1-31.

Deichmann, W. B. and Keplinger, M. L. 1981. Phenols and phenolic compounds. In: Clayton, G. D. and Clayton, F. E. (Eds.), Patty's industrial hygiene and toxicology, vol. 2A, Wiley-Interscience, New York, p. 2601-2604.

Ellman, G. L. 1959. Tissue sulfhydryl group. Arch. Biochem. Biophys., 82: 70-77.

EPA 2002. Methods for measuring the acute toxicity of effluents and receiving waters to freshwater and marine organisms, $5^{\text {th }}$ edn. US Environmental Protection Agency, Washington, DC (EPA-821-R-02-012).

Finney, D. J. 1971. Probit analysis, $3^{\text {rd }}$ edn. Cambridge University Press, New York, 337 pp.

Girotti, A. W. 1998. Lipid hydroperoxide generation, turnover and effect or action in biological systems. J. Lipid. Res., 39: $1529-1542$.

Gull, S., Belge-Kurutas, E., Yildiz, E., Sahan, A. and Doran, F. 2004. Pollution correlated modifications of liver antioxidant system and histopathology of Cyprinidae living in Seyhan Dam Lake, Turkey. Environ. Int., 30: 605-609.

Irons, R. D. 1981. Inhibition of lymphocyte transformation and microtubule assembly by quinine metabolites of benzene: evidence for a common mechanism. J. Reticuloendot. Soc., 3: $359-372$

Kakkar, P., Das, B. and Viswanathan, D. N. 1984. A modified spectrometric assay of superoxide dismutase. Ind. $J$. Biochem. Biophys., 21: 130.
Kappus, H. and Sies, H. 1981. Toxic drug effects associated with oxygen metabolism: redox cycling and lipid peroxidation. Experientia, 37(12): 1233-1241.

Leaver, M. J. and George, S. G. 1998. A piscine glutathione-Stransferase which efficiently conjugates the end products of lipid peroxidation. Mar. Environ. Res., 46: 71-74.

Leaver, M. J., Clarke, D. J. and George, S. G. 1992. Molecular studies of the phase II xenobiotic conjugative enzymes of marine Pleuronectid flatfish. Aquat. Toxicol., 22: 265-278.

Lowry, O. H., Rosenbrough, N. J., Farr, A. L. and Randoll, R. J. 1951. Protein measurement with folin phenol reagent. J. Biol. Chem., 193: 265-275.

Lushchak, V. I., Lushchak, L. P., Mota, A. A. and Hermes-Lima, M. 2001. Oxidative stress and antioxidant defenses in gold fish Carassius auratus during anoxia and reoxygenation. Am. J. Physiol. Regul. Integr. Comp. Physiol., 280: 100-107.

Maehly, A. C. and Chance, B. 1955. Assay of catalases and peroxidases. In: Colowick, S. P. and Kaplan, N. O. (Eds.), Methods in enzymology, vol. II, Academic Press, New York, London, p. 357-424.

Mair, R. D. and Hall, R. T. 1971. Determination of organic peroxides by physical, chemical and colorimetric methods. In: Daniel Swern (Ed.), Organic peroxides, vol. 2, Wiley Interscience Publishers, New York, p. 535-538.

Mannaerts, G. P. and Van Veldhoven, P. P. 1993. Metabolic pathways in mammalian peroxisomes. Biochimie, 75: 147-158.

Nam, Y., Cho, Y., Choi, B., Kim, K., Kim, S. and Kim, D. 2005. Alteration of oxidative enzyme at the mRNA level during short-term starvation of the rockbream, Oplegnatus fasciatus. Fish. Sci., 71: 1385-1387.

Niehaus, W. G. Jr. and Samuelson, B. 1968. Formation of malondialdehyde from phospholipid arachidonate during microsomal lipid peroxidation. Eur. J. Biochem., 6: 126-130.

OECD 2000. Guidance document on aquatic toxicity testing of difficult substances and mixtures, Series on testing and assessment No. 23. OECD Environment Directorate; Organisation for Economic Co-operation and Development, Paris, 53 pp.

Penning, T. M., Ohnishi, S. T., Ohnishi, T. and Harvey, R. G. 1996. Generation of reactive oxygen species during the enzymatic oxidation of polycyclic aromatic hydrocarbon transdihydrodiols catalysed by dihydrodiol dehydrogenase. Chem. Res. Toxicol., 9: 84-92.

Retnagol, R. O. and Ghoshal, A. K. 1966. Quantitative estimation of peroxidative decomposition of rat liver microsomal and mitochondrial lipids after carbon tetrachloride poisoning. Exp. Mol. Pathol., 5: 413-426.

Rodriguez-Ariza, A., Dorado, G., Peinado, J., Pueyo, C. and Lopez-Barea, J. 1991. Biochemical effects of environmental pollution in fishes from Spanish South-Atlantic littoral. Biochem. Soc. Trans., 19: 301. 
Rondon-von Osten, J., Ortiz-Arana, A., Guilhermino, L. and Soares, A. M. V. M. 2005. In vivo evaluation of three biomarkers in the mosquito fish (Gambusia yucatana) exposed to pesticides. Chemosphere, 58: 627-636.

Rotruck, J. J., Pope, A. L. Ganthe, H. E., Swanson, A. B., Hafeman, D. G. and Hoekstra, W. G. 1973. Selenium: biochemical role as a component of glutathione peroxidase. Science, 179: 588-590.

Sawahata, T. and Neal, R. A. 1983. Biotransformation of phenol to hydroquinone and catechol by rat liver microsomes. Mol. Pharmacol., 23: 453-460.

Sayeed, I., Parvez, S., Pandey, S., Bin-Hafeez, B., Haque, R. and Raisuddin, S. 2003. Oxidative stress biomarkers of exposure to deltamethrin in freshwater fish, Channa punctatus Bloch. Ecotoxicol. Environl. Safe., 56: 295-301.

Saeed, T. and Al-Mutairi, M. 1999. Chemical composition of the water-soluble fraction of leaded gasolines in seawater. Environ. Int., 25: 117-29.

Scott, K., Leaver, M. and George, S. 1992. Regulation of hepatic glutathione-S-transferase expression in flounder. Mar. Erviron. Res., 34: 233.

Sreejai, R. and Jaya, D. S. 2010. Studies on the changes in lipid peroxidation and antioxidants in fishes exposed to hydrogen sulfide. Toxicol. Int., 17: 71-77.
Stein, J. E., Collier, T. K., Reichert, W. L., Casillas, E., Horn, T. and Varanasi, U. 1992. Bioindicators of contaminant exposure and sublethal effects: studies with benthic fish in Puget Sound, Washington. Environ. Toxicol. Chem., 11: 701-714.

Wallin, H., Melin, P., Schelin, C. and Jergil, B. 1985. Evidence that covalent binding of metabolically activated phenol to proteins is caused by oxidized products of hydroquinone and catechol. Chem. Biol. Interact., 55: 335-346.

Wilhelm- Filho, D., Torres, M. A., Zanibonifilho, E. and Pedrosa, R. C. 2005. Effect of different oxygen tensions on weight gain, feed conversion, and antioxidant status in piapara, Leporinus elongatus (Valenciennes, 1847). Aquaculture, 244: 349-357.

Winston, G. W. and Di Giulio, R. T. 1991, Pro-oxidant and antioxidant mechanism in aquatic organisms. Aquatic. Toxicol., 19: 137-161.

Zhang, J., Shen, H., Wang, X., Wu, J. and Xue, Y. 2004. Effects of chronic exposure of 2, 4-dichlorophenol on the antioxidant system in liver of freshwater fish Carassius auratus, Chemosphere, 55: 167-174. 